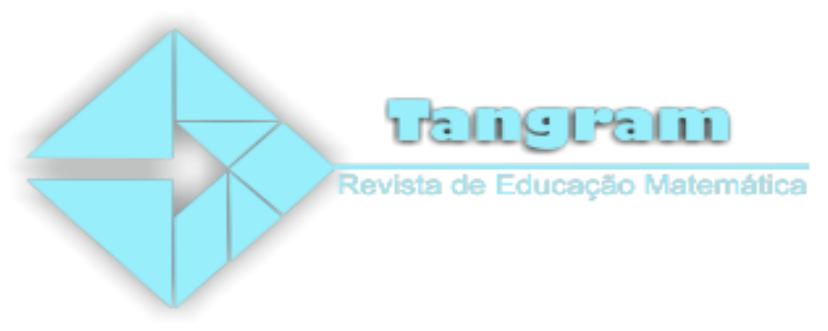

\title{
O ensino de probabilidade com questões sociais
}

\section{The probability education with social issues}

\author{
Márcio José Silva ${ }^{1}$ \\ Fábio José da Costa Alves ${ }^{2}$ \\ Claudianny Amorim Noronha ${ }^{3}$
}

\begin{abstract}
Resumo: Objetivando verificar se o uso da sequência didática, envolvendo situações sociais do município de Abaetetuba, torna o ensino e aprendizagem de probabilidade atraente é que se efetivou o presente artigo; parte integrante de uma pesquisa realizada no Mestrado em Educação da Universidade do Estado do Pará. O cabedal metodológico tem seu respaldo na Educação Matemática Critica de Skovsmose (2008), traduzido por Abreu (2012). Fundamentada em autores como: Passos (2008); Rotunno (2007), Reis (2010), Canaveze (2013); Lima (2013); Vargas (2011); Neves (2015); Souza (2012), entre outros, que justificam um ensino de Matemática propiciador da formação crítica dos alunos, realizou-se, primeiramente, um experimento de validação da sequência didática, a qual construído a partir da contribuição de 5(cinco) alunos do curso de Licenciatura Plena em Matemática de uma Universidade Pública da região. Após tal procedimento, utilizou-se do experimento didático, previamente confeccionado, em turma do $2^{\circ}$ ano do Ensino Médio, com 30 (trinta) alunos, com idades entre 15 e 19 anos, pertencentes a uma escola estadual do município de Abaetetuba/PA. Assim, os resultados do pré e pós-teste apontaram para a necessidade de se trabalhar parte da álgebra básica, atrelada à interpretação de texto, estes em concomitância com o ensino e aprendizagem de probabilidade. Assim, os dados da pesquisa levam a inferir que, tanto na fase da validação quanto na de experimentação didática, as atividades se mostraram estimulantes no que concerne ao fomento da cognição crítica por parte dos alunos, a ponto de revelar um processo de aprendizagem matemática prazeroso e significativo.
\end{abstract}

Palavras-chave: Ensino de Probabilidade; Micro gênese; Questões Sociais.

Abstract In order to verify if the use of the didactic sequence involving social situations of the municipality of Abaetetuba makes the teaching and learning of probability attractive is the basis for this arcticle. This is an integral part of a research carried out in the Master's Degree in Education of the State University of Pará. The methodological background has its support in the Critical Mathematical Education of Skovsmose (2008), translated by Abreu (2012). Based on authors such as: Passos (2008); Rotuno (2007), Reis (2010), Canaveze (2013); Lima (2013); Vargas (2011); Neves (2015); Souza (2012), among others that justify a teaching of Mathematics propitiating the critical formation of the students was carried out firstly as a validation experiment of the didactic sequence which was constructed from the contribution of 5 (five) students of the course Full Degree in Mathematics from a Public University in the region. After this procedure, we used the didactic experiment previously made in a group of the second year of high school with 30 (thirty) students aged 15 to 19 years old belonging to a state school in the municipality of Abaetetuba / PA. Thus, the

${ }^{1}$ Docente efetivo da universidade do estado do Pará-UEPA. Dmei(Departamento de matemática, estatística e informática).

${ }^{2}$ Doutor em Geofísica/UFPA. Docente e Pesquisador da UEPA/UNAM

${ }^{3}$ Professora associada do Departamento de Prática Educacionais e Currículo da Universidade Federal do Rio Grande do Norte (UFRN) e dos Programa de Pós-Graduação em Ensino de Ciências Naturais e Matemática, do Doutorado em Ensino de Ciências e Matemática e do Programa de Pós-Graduação em Educação.

Tangram - Revista de Educação Matemática, Dourados - MS - v.2 n.2, pp. 47 - 66 (2019) 


\section{$O$ ensino de probabilidade com questões sociais}

results of the pre and post-test pointed to the need to work part of the basic algebra linked to the interpretation of text in concomitance with the teaching and learning of probability. The research data led us to infer that in both the validation and didactic experimentation phases, the activities were stimulating in relation to the promotion of critical cognition on the part of the students, to the point of revealing a process of pleasant and significant mathematical learning.

Key-words: Teaching of Probability. Micro genesis. Social questions

\section{Introdução}

Frente às novas expectativas da educação matemática, a formação cidadã dos alunos passa a ser um objetivo a ser alcançado pelos professores dessa área do saber, os quais devem buscar a ressignificação de seus conteúdos; trabalhando o senso crítico do discente em paralelo ao exercício da cidadania deste. Nesse contexto, para Abreu (2012, p.21), as novas metodologias consideram os problemas sociais, políticos e culturais que permeiam a sociedade a fomentar que valorizem o racional, a fim de possibilitar a libertação e conscientização do ser humano, constituiu espaço fecundo para "Teoria Crítica". Já para Passos (2008, p. 34), essa teoria está apoiada na dialética do esclarecimento, um conceito mais abrangente de razão que visa a formulação da concepção de uma práxis transformadora e que propõe a linguagem como um modo de ação.

O mencionado autor ainda informa que a partir da década de 60, no Brasil, o Movimento da Matemática Moderna (MMM) "pretendia revolucionar o Ensino de Matemática por meio de mudanças das propostas curriculares de matemática" (PASSOS, 2008, p. 35), ação geradora de novas diretrizes ao currículo de Matemática, sobretudo no que tangue ao ensino primário e secundário dessa área do saber. Nesse período, ainda informa o citadino autor, é que surgiram outras perspectivas na Educação Matemática, muito embora as ideologias defendidas pelo Movimento da Matemática Moderna (MMM) não convergissem especificamente, em termos de conteúdos matemáticos, como o que defendida a Educação Matemática Crítica, na qual o desempenho dos estudantes, quanto ao desenvolvimento do senso crítico, permearia conteúdos reais de situações sociais por eles vivenciadas, isto é um ensino próximo à realidade cotidiana dos educandos.

No que concerne a importância do papel da Matemática Crítica na educação para vida, Abreu (2012, p.24), em consonância com Passos (2008), elucida que:

[...] se queremos educar criticamente os nossos alunos então "os problemas não devem pertencer a "realidade de faz-de-conta" sem nenhuma Tangram - Revista de Educação Matemática, Dourados - MS - v.2 n. 2, pp. 47-66 (2019) 


\section{$O$ ensino de probabilidade com questões sociais}

significação exceto como ilustração da matemática como ciência das situações hipotéticas". [...]" se nas aulas não "arranjarmos" espaço para o diálogo, para a partilha de opiniões e para a discussão de temas que despertem a curiosidade dos alunos, arriscamo-nos a que, mesmos os mais curiosos e críticos passem a aceitar tudo o que lhes é dito sem questionar.

Em complemento as assertivas acima Reis (2010), corrobora que:

$\mathrm{Na}$ perspectiva da Educação Matemática Crítica (EMC), ensinar matemática que tenha significado e que direcione o aluno a uma reflexão crítica de sua realidade social implica educar de forma democrática, possibilitando que todos participem ativamente, como sujeitos, na sociedade. Esta se configura como uma das maiores preocupações nas obras de Skovsmose (2008) em suas teorizações acerca do tema: a Educação Matemática não se restringe à técnica de ensinar matemática, contudo se configura como um ato de educar matematicamente para a vida. (Reis, 2010, p.39)

Sendo assim, "na educação matemática crítica a educação matemática é centrada na pessoa”, (ABREU, 2012, p. 28), ou seja, prepara o aluno para exercer a democracia e ser um cidadão crítico e consciente. A partir de esse "novo olhar" matemático, permear o ensino de probabilidade é um tópico de grande relevância na Educação Matemática, pois permite a resolução de problemas do cotidiano, ajudando na tomada de decisões. Em vista do exposto, é importante ressaltar que o estudo da probabilidade aqui tratado, está vinculado à Modelagem Matemática, em que trata de experimentos ou eventos cujos resultados são gerados de forma aleatória - são considerados exemplos de experimentos aleatórios: o resultado de uma partida de futebol, as faces observáveis em dois lançamentos de um dado, e também na representatividade de uma moeda, ou até mesmo o sorteio ou a possibilidade de se ganhar na loteria.

A partir do exposto, outro autor que trata de experimentos aleatórios via estudo da probabilidade é Gondim (2013). Para ele, é grande a necessidade de abordar, de forma diferente, esse tema através do uso, não só dos clássicos problemas envolvendo jogos de azar, mas também, abranger situações que tratem com frequência, problemas geométricos, experimentos práticos para serem aplicados em sala de aula, pois, em qualquer ambiente escolar as questões ou assuntos que sempre irão despertar e ter maior evidência de interesse nos alunos são àquelas questões voltadas às situações do dia a dia.

Dada a importância da probabilidade, é preciso conhecer sua origem histórica e, para isso recorreu-se a Iung (2013, p. 14) ao afirmar que:

Tangram - Revista de Educação Matemática, Dourados - MS - v.2 n. 2, pp. 47-66 (2019) 


\section{$O$ ensino de probabilidade com questões sociais}

A probabilidade teve origem por volta do século XVII com Pascal e Fermat que resolveram questões relacionadas a jogos de azar e em sua histórica correspondência de 1654, refletiram sobre outros problemas relacionados com o problema dos pontos [...]. Foi esse trabalho de Pascal e Fermat que lançou as bases da teoria matemática da probabilidade. Nos dois séculos seguintes, estudiosos como Bernoulli, Moivre, Euler, Lagrange, Laplace, entre outros, formalizaram os conceitos.

A esse respeito, Gondin (2013, p. 3) também corrobora acrescentando que:

O primeiro registro sobre o estudo de probabilidade surgiu com Girolamo Cardano (Itália, 1501 - 1576) que, em 1526 escreveu um trabalho notável sobre probabilidades, o livro Liber de Ludo Aleae(Livro dos jogos de azar) no qual resolveu vários problemas de enumeração. A obra de Cardano, porém, só foi publicada em 1663.

Outro autor de grande relevância acerca das origens históricas da Probabilidade é Rotuno (2007), sobretudo ao frisar que em 1963, se iniciaram várias investigações de compilação de informação no que tange ao censo populacional referente aos nascimentos, casamentos e taxa de mortalidade apoiados no desenvolvimento da estatística descritiva; o que permitiria a probabilidade de um sucesso a posteriori em função de uma probabilidade apriori.

No demais, Rotuno (2007) ratifica que no final do século VXIII e início do sec. XIX, com a Revolução Francesa a qual pregava o sentimento de liberdade, surgiram outros grandes cientistas profissionais na matemática, como Lagrange e Gauss que, os quais puderam expandir os estudos em Educação, matemática, já que:

[...] fundamentaram e desenvolveram a Análise Matemática, cuja aplicação, somada ao Cálculo de Probabilidades, permite lançar mão de instrumentos aritméticos e combinatórios. A ampliação e aplicação em campos concretos desses trabalhos facilitaram e transformaram esse ramo da matemática pura que hoje conhecemos (Rotuno, 2007, pg. 20).

No bojo das discussões teóricas, surge Gonçalves (2004) e seus constructos a respeito da Educação Matemática, atrelada ao estudo da probabilidade pelo viés da Educação Matemática Crítica, isso ao analisar os livros didáticos no Brasil e, observar que algumas orientações institucionais, a partir da década de 70, elencavam algum tipo de relação entre

Tangram - Revista de Educação Matemática, Dourados - MS - v.2 n. 2, pp. 47-66 (2019) 


\section{O ensino de probabilidade com questões sociais}

as concepções atuais dos professores de Matemática em exercício no Ensino Fundamental e as diferentes tendências do Ensino de Probabilidade nas décadas de 70, 80 e 90. Assim, tomando por base os estudos de Yves Chevellard (1995), ele constatou a existência de algumas informações referentes ao tipo de concepção e período de formação básica e de indícios de que a prática docente influencia na mudança de concepções em torno do Ensino de Probabilidade, porém, pouco ou quase nada se tem escrito sobre o surgimento do Ensino de tal conteúdo no Brasil.

De acordo com Ferreira (2011, p. 22), até a década de 70, o Ensino de Probabilidades tinha como visão norteadora o olhar clássico ensejada no cálculo combinatório onde a maioria dos professores via tal conteúdo como uma parte secundária da matemática pelo fato deste estar centrado na ideia de jogo; portanto, suas aplicações não eram valorizadas nas mais diferentes partes da ciência, pois, o raciocínio combinatório era trabalhado de uma maneira muito complexa o que levava muitos alunos a acharem difícil a sua abordagem. Nesse período, observaram-se muitos avanços com o advento da teoria dos conjuntos, que segundo Ferreira (2011), reservara um maior interesse pela probabilidade matemática o que facilitava sua aplicabilidade tanto pela sua simplicidade quanto pela ligação que esta teoria tinha com a realidade do aluno.

No que se refere ao Ensino de Probabilidade os PCNS (1997, p. 19 e 45), informam que:

São necessárias noções de probabilidade, análise combinatória e bioquímica para dar significado às leis da hereditariedade, o que demanda o estabelecimento de relações de conceitos aprendidos em outras disciplinas. [...] as habilidades de descrever e analisar um grande número de dados, realizar inferências e fazer predições com base numa amostra de população, aplicar as ideias de probabilidade e combinatória a fenômenos naturais e do cotidiano são aplicações da Matemática em questões do mundo real que tiveram um crescimento muito grande e se tornaram bastante complexas.

De tal modo, o estudo da teoria de probabilidade tem por base autores como: Rotuno (2007), Canaveze (2013), Gondin (2013), Iung (2013), entre outros; porém, ainda que dada a grande contribuição de tais pesquisadores, há de se destacar que esse campo na Educação Matemática, sobretudo a Crítica - Ensino de Probabilidade - ainda é recente; o que acarreta escassa produção científica cujo foco seja o aludido assunto. Então, diante da "escassez" de material encontrado, assim como da importância dessa área do saber, o proponente deste estudo resolveu lançar-se ao desafio em trabalhar o Ensino de Probabilidade, partindo da Tangram - Revista de Educação Matemática, Dourados - MS - v.2 n. 2, pp. 47-66 (2019) 


\section{O ensino de probabilidade com questões sociais}

aplicação da teoria da aprendizagem significativa, em que o núcleo central é a Educação Matemática Crítica.

Todavia, antes de prosseguir nas elucubrações a respeito do ensino de probabilidade via teoria da aprendizagem significativa, aqui cabe um adendo, a saber: durante a realização da pesquisa, constataram-se algumas premissas científicas, as quais serviram de norte a construção dessa inquirição, quais sejam:

- Os estudos de Canaveze (2013), sobre "O Ensino-Aprendizagem de Probabilidade em uma escola pública de Sorocaba/SP”, onde a autora afirma que uso de diferentes registros de representação, de acordo com os pressupostos teóricos de Raymond Duval colaborou bastante para consolidar a aprendizagem dos alunos no que tange ao conteúdo probabilístico;

- O trabalho de Lima (2013), onde o autor ratifica e conclui que a proposta didática apresentada durante seu trabalho foi muito eficaz, pois, tornou suas aulas mais motivadoras gerando um ambiente em que os alunos puderam aprender Probabilidade exercendo sua capacidade criativa;

- Os Estudos de Vargas (2011), em que o autor afirma que são muitas as dificuldades que o educador encontra em motivar e mobilizar o aluno a se desenvolver no processo de ensino aprendizagem para que este tenha mais vontade e, possa ter uma atividade intelectual concernente ao Ensino de Probabilidade e suas contribuições para a vida;

- O trabalho de Neves (2015), que tratou do "Ensino de Probabilidade: Tipos de eventos", no qual o autor advoga que é de grande urgência uma abordagem em sala de aula pelos professores, de novas técnicas e maneiras de se trabalhar o conteúdo de probabilidade levando-se em consideração o experimento, pois, há pouca relevância no tratamento desse assunto nos livros didáticos relativo ao um ensino vinculado a sua historicidade e o elo existente entre os jogos e a teria de probabilidade;

- Os estudos de Souza (2012), sobre "Proposta de Ensino para conceituação de Acaso como introdução ao Ensino de Probabilidade", em que o autor afirma que a maioria dos alunos que participaram de sua pesquisa demonstrou cansaço durante as atividades e, que mesmo com esse problema o resultado foi promissor; além disso, o autor afirma que os alunos participantes de sua pesquisa

Tangram - Revista de Educação Matemática, Dourados - MS - v.2 n. 2, pp. 47-66 (2019) 


\section{$O$ ensino de probabilidade com questões sociais}

apresentaram mudanças no modo de entender e se relacionar com o acaso presente no dia a dia; dentre outros.

Mediante ao exposto, buscou-se responder a seguinte indagação: O Ensino de Probabilidade via questões sociais possibilita sua aprendizagem de forma mais atraente e sólida?

Para responder aquela indagação, adotou-se como objetivo fundamental, verificar se uma sequência de atividades de probabilidade envolvendo 4 atividades com 40 questões sobre o conceito de probabilidade, Probabilidade condicional, teorema de Bayes e o princípio multiplicativo, construídas com dados reais extraídos de pesquisas envolvendo situações vivenciadas por muitos adolescentes, tais como: o uso de drogas entre adolescente, acidentes de trânsito, moradores de rua, desemprego, abandono, o Bullying, gravidez na adolescência, baixo índice de desempenho escolar, pornografia digital, prostituição, entre outros

Para avaliar a sequência didática, antes de sua aplicação na Educação Básica, foi feito um experimento de validação das atividades, envolvendo 5 (cinco) alunos colaboradores do curso de graduação em matemática da Universidade do Estado do Pará (UEPA), na Cidade de Abaetetuba, localizada na Meso Região do Nordeste Paraense pertencente a Microrregião de Cametá, os quais apresentaram sugestões para melhorar a eficiência da sequência didática. Sendo coletados dados em áudio durante a validação da atividade e em grupo focal, procedimento baseado nos estudos de Cabral (2004), sobre a teoria da micro gênese desenvolvida para analisar as interações verbais dos alunos participantes da pesquisa, que na visão $\operatorname{Gondim}(2013$, p. 151):

É uma técnica de pesquisa que coleta dados por meio das interações grupais ao se discutir um tópico especial sugerido pela pesquisadora Como técnica, ocupa uma posição intermediária entre a observação participante e as entrevistas em profundidade. Pode ser caracterizado também como um recurso para compreender o processo de construção das percepções, atitudes e representações sociais de grupos humanos.

No experimento de validação, inicialmente, foi entregue aos alunos colaboradores um livreto com as atividades. E, durante a experimentação, após um período inicial de leitura e apropriação do texto pelos alunos colaboradores, o pesquisador fez algumas indagações a respeito da possibilidade e da viabilidade do uso da atividade para o ensino de probabilidade no Ensino Médio.

Tangram - Revista de Educação Matemática, Dourados - MS - v.2 n. 2, pp. 47-66 (2019) 


\section{O ensino de probabilidade com questões sociais}

Frente aos questionamentos do pesquisador, os alunos colaboradores, cujas identificações, por questões éticas em pesquisa com seres humanos, serão designadas pelas letras do alfabeto A, B, C, D e E, mantiveram a seguinte relação dialógica: Pesquisador:

"As questões propostas refletem alguma realidade vivenciada durante sua adolescência?"

\section{- Registro de voz do aluno (A):}

"Sim, alguns textos eu mesma, vivenciei, presenciei. E outras situações foram com pessoas próximas. Então tudo o que está no texto é relacionado ao nosso dia a dia. Isso chama a nossa atenção e o que nos familiariza para resolver”.

\section{- Registro de voz do aluno (B):}

"Sim! É vivenciei algumas coisas que estavam no texto e outras, amigos meus e vizinhos já viveram”.

- Registro de voz do aluno (C):

"Sim, as minhas colegas, muitas engravidaram e abandonaram o estudo. E nessas questões abordadas nesses textos o aluno vai ficar mais atento a esses temas e vai tomar mais cuidado; digamos assim, vai ficar mais [...], ele vai ta conhecendo. Ele vai saber o risco que tá correndo. E como ele já vai conhecer ele vai evitar essas situações”.

- Registro de voz do aluno (D)

"Sim, até porque os textos mencionam os temas tipo a gravidez na adolescência, o bullying, [...]. Essas questões eu vivenciei na escola”. "Por que as vezes é por descuido do pai ou da mãe, não sei, do responsável que acaba ocorrendo na vida do adolescente e por consequências de atitudes de outras pessoas [...]".

Pesquisador:

"Essas questões chamam a atenção do aluno para aprender probabilidade?"

\section{- Registro de voz do aluno (B):}

"Eu achei interessante, assim, essa proposta de usar esses temas no texto porque vai chamar a atenção do aluno".

Tangram - Revista de Educação Matemática, Dourados - MS - v.2 n. 2, pp. 47-66 (2019) 


\section{$O$ ensino de probabilidade com questões sociais}

\section{- Registro de voz do aluno (C):}

"Sim, ele vai ter aquele interesse porque muita gente pega texto que agente nem sabe do que se trata. Ai é uma forma de chamar a atenção do aluno e buscar o interesse dele pelo estudo".

\section{- Registro de voz do aluno (E):}

"Sim, porque, [...] não comigo, não aconteceu mais com a minha família sim. Algumas pessoas sofreram Bullying, então isso chama de alguma forma a atenção. Tipo; tá contextualizando a matemática com o dia a dia do aluno com o que ele esta vivenciando. Então vai chamar a atenção dele de alguma forma para aprender".

Pesquisador:

"Esses modelos de questões ajudam o aluno a entender e aprender os princípios do cálculo de probabilidade”?

\section{- Registro de voz do aluno (A):}

"Não só ajuda quanto desperta o interesse maior, pois, como os dados são verídicos o aluno fica interessado em determinadas partes, um exemplo disso, é o da nossa cidade de Abaetetuba onde o número de alunos com uma determinada idade que é no caso a probabilidade condicional de estarem gravidas. Então ele define um número total das adolescentes gravidas, porém dá a condição, por exemplo, a idade de quinze anos... o aluno vai despertar o interesse dele de ver que é [...], são números altos, pois são coisas que eles poderiam tá evitando. São coisas do dia a dia..."

- Registro de voz do aluno (C):

"Sim, parque quando a gente senta para resolver esse tipo de questão agente pode ver que, tipo assim, a questão da teoria e a probabilidade; a gente aprende na escola que você vai pegar um número de eventos possíveis pelo total. Mais ai quando você resolve você pode ver que você; claro, você vai resolver assim, mais ai essa parte de você fazer essa probabilidade do teorema de probabilidade [...], você vai usar nas outras também e ai, você só vai acrescentar outras coisas a mais tipo o teorema de Bayer; você já vai ter a probabilidade de ocorrer um evento sendo que já ocorreu outro [...] e; isso trazendo pro seu dia a dia. [...], vai ter a condição. Ocorreu um que vai condicionar a ocorrência do outro. Ai trazendo pro dia a dia tipo; nós podemos ter como tinha nos textos, uma pessoa

Tangram - Revista de Educação Matemática, Dourados - MS - v.2 n. 2, pp. 47-66 (2019) 


\section{$O$ ensino de probabilidade com questões sociais}

esta gravida e ela estudar ou não, saber ler, tipo assim, estar na escola ou não estar na escola, tipo, tinham várias condições e, isso ajuda a pessoa a aprender o conteúdo".

Pesquisador:

"Essas questões tem algum significado para a sua vida”?

- Registro de voz do Aluno (B):

"Sim! É, uma coisa que eu achei interessante. [...] quando eu estudei não me mostraram o teorema, não me mostraram essas maneiras. Essas formas diferentes [...]. Então; é, são maneiras boas de chamar a atenção do aluno porque agente estuda aquela probabilidade normal que a gente vê, ai quando eu pequei isso, eu achei até interessante de analisar porque vai chamar a atenção do aluno de qualquer forma. Tipo, eu não aprendi dessa forma, mas eu posso aprender dessa outra. São maneiras boas de chamar a atenção do aluno e que acho que deveriam apresentar nas escolas [...], sobre um determinado assunto."

- Registro de voz do aluno (E):

"Sim, é bastante significativo, pois apresenta situação que está dentro, é claro, da nossa cultura, entende? [...]. É; a gente vê isso muito aqui no estado do Pará. Então, observa muito bem isso no texto, né, com relação às situações; se aprende. Dá sim pra aprender probabilidade porque a gente percebe que essas coisas estão ao redor, né, e são bem observadas no texto e, assim, se torna mais fácil é resolver os cálculos da probabilidade, tanto do teorema de Bayer ou multiplicação ou regra do produto, né [...], é isso"

- Registro de voz do aluno (D):

"Sim, pois, devido relacionar o dia a dia do aluno com a probabilidade, se torna uma coisa bem mais interessante pra ele resolver, tipo, não se torna uma coisa chata sempre ele tem textos diferentes como Bullying, gravidez e, também, o uso de drogas. Então, tudo isso chama a atenção dele pra resolver essas questões e se torna bem mais fácil dele resolver com esse método. É uma coisa inovadora. Coisas que agente não viu no nosso Ensino Médio".

Pesquisador:

“Ao ler e resolver as questões você se sentiu inserido no contexto das questões”?

- Registro de voz do aluno (E):

Tangram - Revista de Educação Matemática, Dourados - MS - v.2 n. 2, pp. 47-66 (2019) 


\section{O ensino de probabilidade com questões sociais}

"É, quando eu comecei a ler o texto, percebi assim, que me vi inserido dentro do texto quando ele se refere a sexualidade, ou até mesmo quando ele fala sobre masturbação lá né, então, acho assim que tem muitas coisa, assim que chama e atrai a atenção do adolescente e do jovem, né, com respeito a sexualidade [...]"

Observou-se, através das respostas dos alunos colaboradores, que o contexto das questões propostas, bem como a forma de como elas foram construídas, não só refletem situações que fazem parte da vida diária da maioria dos discentes do Ensino Médio, como também incentiva e entusiasma o alunado a resolver problemas matemáticos, pois estabelece uma estreita relação entre conteúdo escolar e os problemas que cercam o cotidiano daqueles. Para os alunos colaboradores, as atividades propostas incentivam a refletir a respeito de dada realidade, como também dos fenômenos sociais, estimulando o senso crítico, ajudando o despertar do aluno para sua realidade; contribuindo, desta maneira, com a formação cidadã dos mesmos, tornando-os mais conscientes e críticos.

Durante o experimentação de validação das atividades pode-se perceber que todos os 5 (cinco) alunos colaboradores estavam muito entusiasmados por ver nas leituras das questões muitas situações vivenciadas por eles durante sua adolescência e por muitos colegas com os quais convivem, ou seja, o fato dessas questões tratarem de realidades envolvendo problemas vivenciados e/ou observados por esses alunos, tais como, o Bullying, o uso de drogas, o consumo de cigarros, as DSTS, o baixo rendimento escolar; dentre outros, fazem com que seus interesses em resolver problemas e refletir sobre essas realidades presentes em seu dia a dia despertam tanto o entusiasmo quanto o interesse em resolver essas questões.

Como a fase de validação, percebeu-se que as atividades são bem elaboradas e são viáveis a serem aplicadas em experimentos didáticos posteriores na Educação Básica, pois não só prendem a atenção do alunado, por tratar de situações vivenciadas por eles em seu convívio diário e social, como ainda facilita o aprendizado de probabilidade, já que são questões que trazem em germe dados reais sobre os mais diversos problemas vivenciados por adolescentes, não só fora como dentro do espaço de convívio familiar e escolar.

Depois de feitas as correções necessárias, no texto das atividades, apontadas pelos alunos colaboradores, na fase de validação com objetivo de melhor a eficiência dessas no processo de ensino e aprendizagem de probabilidade, produziu-se um pré-teste e um pósteste contendo 8 (oito) questões sócio críticas, sendo utilizado o pré teste para verificar o

Tangram - Revista de Educação Matemática, Dourados - MS - v.2 n. 2, pp. 47-66 (2019) 


\section{O ensino de probabilidade com questões sociais}

conhecimento prévio dos alunos sobre probabilidade e o pós teste para mensurar o conhecimento adquirido pelos alunos durante o experimento. Sendo também utilizado a micro genético, com o objetivo avaliativo das reações dos alunos, do Ensino Básico, com o uso da atividade proposta.

Já com as atividades validadas aplicou-se o experimento didático em uma sala de aula do $2^{\circ}$ ano do Ensino Médio de uma escola pública do município de Abaetetuba, com 30 (trinta) alunos, com idades que variavam de 15 a 19 anos. É importante destacar que durante a experimentação didática, foi efetivado o registro de voz, propiciando dados que retrataram o sentimento e comportamento dos alunos durante a experimentação.

O experimento iniciou 14/11/2016 com a aplicação de um pré-teste, estando presentes 30 (trinta) alunos dos 35 (trinta e cinco) matriculados na turma. Durante a aplicação do pré-teste houve muita indagação quanto à resolução das questões. Na tentativa de solucionar as questões do pré-teste, a maior parte do alunado usou o pré-saber adquirido na disciplina de biologia que utilizou certa parte do conhecimento de probabilidade do seu conteúdo. Por outro lado, esses mesmos alunos afirmavam, entre si, nunca haver visto esses modelos de questão e nem estudado esse tipo de cálculo. E perguntavam: "Professor, como se resolve isso? São questões grandes! E falam de coisas que existem aqui na escola. Por que isso?".

No dia 21 de novembro de 2016, aplicou-se a primeira atividade, a qual tratava da definição de probabilidade. A aula iniciou às 7 h e encerrou às 8 h30min. Nesse dia explicouse aos alunos algumas definições envolvendo probabilidade e suas aplicações; momento em que abordou-se também os conceitos de probabilidade objetiva, subjetiva e axiomática. $\mathrm{Na}$ ocasião, mostrou-se as propriedades da probabilidade e axiomas. No decorrer da aula expositiva, foram lançadas e resolvidas algumas questões envolvendo o assunto e, posteriormente, solucionadas três das atividades propostas, as quais possuíam caráter sócio crítico, envolvendo o assunto em voga.

Na sequência das aulas/experimentação, no dia 22 de novembro de 2016, propôsse 05 (cinco) questões de caráter sócio crítico, a respeito da definição de probabilidade aos alunos; as quais constariam como atividade de fixação e cujo tempo de duração foi de 90 (noventa) minutos para que os alunos, individualmente, pudessem resolver, refletir e discutir.

No terceiro dia de atividade, 28 de novembro de 2016, realizou-se a terceira aula envolvendo o conceito de probabilidade condicional. Ocasião em que enfatizou-se a Tangram - Revista de Educação Matemática, Dourados - MS - v.2 n. 2, pp. 47-66 (2019) 


\section{O ensino de probabilidade com questões sociais}

definição de probabilidade, como ainda apresentou-se alguns exemplos na resolução de questões sociais sobre o assunto em foco. NO decorrer da aula, foram deixadas 5 atividades para os alunos resolverem em sala no próximo dia.

No dia 29 de novembro de 2016, quarto dia de atividades, conforme supramencionado, retomou-se as atividades pendentes da aula anterior, lista que perfazia 5 (cinco) questões de caráter sócio crítico. Cada aluno teve 90 (noventa) minutos para efetuar as resoluções das questões que lhes foram entregues. Nesse dia, ocorreram muitos obstáculos, os quais influenciaram, levemente, o andamento da pesquisa; isto é, a sala de aula ficou inundada por conta de chuva torrencial no município. Recorreu-se, então a outro espaço escolar, mas este encontrava-se muito quente, devido o aparelho de ar condicionado quebrado; contratempos que "atrasaram" a efetivação da aula. Mas que, sanada as dificuldades, não impediram a realização da pesquisa. Todavia, o tempo para a resolução das atividades ficou limitado; ocasionando certo prejuízo para os alunos, já que esses não conseguiam efetuar tais os cálculos, em cada questão proposta no experimento.

No dia 05 de dezembro de 2016 ministrou-se aulas sobre teorema de Bayes e princípio multiplicativo, Período em que se explanou a respeito da definição e propriedades envolvendo tais assuntos, com ainda foram mostrados alguns exemplos de teorema de Bayer e princípio multiplicativo. Por meio das atividades de experimento, os alunos puderam resolver algumas questões de fixação. Vale ressaltar que esses dois últimos conteúdos foram tratados em 90(noventa) minutos de aula, isso por conta do período letivo de avalição escolar que, conforme o calendário institucional dessa unidade educativa, começara no dia no dia 12/12/2016. Daí que foi necessário encerrar o ciclo de atividades avaliativas para a pesquisa em sala.

Ao longo do experimento didático, o pesquisador mantinha sempre um gravador ligado, como também acompanhava todas as atividades de experimentação; ficando sempre próximo aos alunos, de modo a registrar manifestações voluntárias sobre a atividade desenvolvida. Os registros, após transcrição, refletem bem a atmosfera vivida na experimentação didática, em que os alunos demostravam entusiasmo, interesse e participação em estudar o assunto; inclusive identificando-se com as problemáticas propostas nas atividades, fato que pode ser visto com clareza nas fales deles, a exemplo pode-se destacar os recortes de fala dos alunos $\mathrm{A}_{7}, \mathrm{~A}_{12}$, respectivamente.

Tangram - Revista de Educação Matemática, Dourados - MS - v.2 n. 2, pp. 47-66 (2019) 


\title{
$O$ ensino de probabilidade com questões sociais
}

\section{ALUNO A7:}

"Esse assunto aqui sobre probabilidade eu achei muito interessante porque fala do que ocorre no nosso mundo mesmo ao redor de nós. Porque é um assunto que ajuda, que estimula a pessoa a fazer mais. Assim, parece que eu gostei muito [...]para estudar. Parece que, que lá pra frente vou precisar desse assunto para estudar pra prova do ENEM"

\begin{abstract}
ALUNO A 12 :
"Professor o conteúdo dessas questões me faz querer descobrir é; por exemplo, a probabilidade de tá...; de um assunto em que esse conteúdo eu estou inserido dentro dele e a curiosidade me faz querer descobrir sua probabilidade"
\end{abstract}

\section{ALUNO A 22 :}

"Professor essas questões são muito importantes, pois é mostram dados da nossa realidade que a gente vive hoje em dia [...] e, dessa forma a gente consegue aprender probabilidade[...]"

\section{ALUNO $\mathrm{A}_{30}$ :}

“[...] até que é bacana eu acho porque como o senhor ensina da pro cara responder é ... livre a questão .... a questão é boa..."

\section{ALUNO A 13 :}

“[...] Sim porque reflete a minha realidade ajuda pra mim entender mais o assunto probabilidade ..... e, tem coisas no assunto que traz no meu dia a dia”

\footnotetext{
ALUNO A 29 :

"Abrangem temas vividos na escola quanto temas que abrangem toda a sociedade e o aluno se sentindo dentro disso vai, não sei, talvez seja melhor pra ele já que são temas que ele presencia diariamente”
}

ALUNO A 22 :

Tangram - Revista de Educação Matemática, Dourados - MS - v.2 n. 2, pp. 47-66 (2019) 


\section{$O$ ensino de probabilidade com questões sociais}

"Sobre probabilidade que o senhor esta passando os exercícios é, [...], bem acessível pra gente porque também consta ao dia a dia tá contando sobre é ... agressões, sobre racismo e esses assuntos são bem acessíveis pra gente e por isso é bem prático agente trabalhar desse jeito porque a gente aprende ”

\section{ALUNO A $A_{3}$ :}

"[...] deu pra poder entender melhor assim não só a parte de matemática mas a parte do cotidiano porque leva em muito em conta a vida; né. Porque tá contando as histórias assim que acontece e tá ensinando ambas as coisas: a matemática que é a probabilidade que o senhor esta passando e a parte do cotidiano. Então é muito interessante ver essa forma que o senhor passou pra gente"

\section{ALUNA A $A_{11}$ :}

"[...] a estrutura das questões estão falando sobre a nossa realidade, estão mostrando dados que tá incluído na nossa realidade. Às vezes tá falando da gente, da gente mesmo. São dados que tá nos informando. Tá nos alertando contra certos tipos de problemas".

\section{ALUNA A 20 :}

“[...] Eu como aluna consigo sim aprender através dessas atividades o assunto, ele é bem interessante... e, o aluno, ele deveria se interessar porque ele ira se informar nas pesquisas que o apontam [...]"

Conforme análise dos depoimentos dos alunos, percebeu-se o estreitamento da matemática escolar com as questões do dia a dia; o que torna o aprendizado desta disciplina mais significativo e, também estimula o interesse do aluno em aprender, passando este a ter menos dificuldades nos conteúdos propostos, os quais apresentavam certo grau de obstáculos cognitivos. Por isso, a forma de abordar o assunto de probabilidade por meio de atividades envolvendo situações que realmente fazem parte do contexto de vida e experiências desses alunos, fora algo relevante.

Nessa perspectiva, aprender probabilidade ficou mais interessante para os alunos, evidencia destacada no recorte de fala dos alunos $\mathrm{A}_{22}$ e $\mathrm{A}_{30}$. Ação que influi para a assertiva de Moysés (1997, p.31), quanto expõe que: "no processo de internalização os aspectos cognitivos e afetivos mostram-se intimamente entrelaçados" e isso atrelado às situações de Tangram - Revista de Educação Matemática, Dourados - MS - v.2 n. 2, pp. 47-66 (2019) 


\section{O ensino de probabilidade com questões sociais}

vida do aluno relativo às suas atividades experienciais cotidiana, faz com que este manifeste seu interesse em aprender, ação recorrente na mostra de fala dos alunos $A_{13}$ e $A_{29}$ ao indagarem entre si sobre a importância de se aprender uma teoria envolvendo fatos reais.

Após o registro de voz, pode-se perceber que a forma de ensinar probabilidade aqui mencionada foi eficaz e trouxe bons rendimentos cognitivos, uma vez que trata de um conjunto de situações que envolvem experiências de vida, ora presenciada ora experimentada por muitos dos alunos partícipes da aula de experimentação. Ação que se mostrou de grande valia quando se trata de ensinar probabilidade de modo significativo, tal fato fica óbvio nos recortes de fala dos alunos $A_{22}, A_{20}, A_{3}$ e $A_{11}$.

Assim, pode-se constatar que o assunto torna-se bem mais interessante e instigante para o alunado quando tratado de modo contextualizado, a esse respeito Moysés (1997, p.46) contribui ao frisar que o aprendizado do aluno tem maior eficácia e significado quando "o objeto ou elemento figurativo estimula o aluno a pensar"; nesse caso, o elemento figurativo é o modelo de questões com situações do dia a dia do aluno, cujos fenômenos fazem parte de muitas realidades e contextos escolares, os quais podem e devem ser utilizados como subsídio de ensino na disciplina Matemática.

\section{CONSIDERAÇÕES FINAIS}

Etimologicamente a palavra "Probabilidade" é proveniente do latim "probare", que pode ser traduzida como provar ou testar. Essa ação engloba a intenção de se prever possibilidades de ocorrência de uma determinada situação ou fato, o qual pode e deve ser solucionado matematicamente.

Nesse contexto, a pesquisa aqui evidenciada, enquanto parte de investigação científica elaborada no Mestrado em Educação da Universidade do Estado do Pará, visou verificar se uma sequencia de atividades de probabilidade quando abordada por meio de ações do cotidiano torna o ensino de matemática significativo. Assim, após experimento de validação das atividades, onde as opiniões foram unanimes de que tais atividades propostas incentivam a refletir a realidade vivenciada pelos próprios alunos, bem como, dos fenômenos sociais; estimulando e despertando o senso crítico destes, a ponto de contribuir para sua formação cidadã.

Tangram - Revista de Educação Matemática, Dourados - MS - v.2 n. 2, pp. 47-66 (2019) 


\section{O ensino de probabilidade com questões sociais}

Nessa perspectiva, produziu-se um pré-teste e um pós-teste contendo 8 (oito) questões sócio críticas, sendo utilizado o pré teste para verificar o conhecimento prévio dos alunos sobre probabilidade e o pós teste para mensurar o conhecimento adquirido pelos alunos durante o experimento, utilizando a micro genético, com o objetivo de avaliar as reações dos alunos, do Ensino Básico, com o uso da atividade proposta.

Entretanto, na experimentação didática, os resultados do pré-teste demostraram que a maioria dos alunos não dominava o assunto e, apesar de terem contato com a probabilidade na disciplina matemática, seu conhecimento sobre o conteúdo era restrito/superficial. Em consequência disso, o resultado do pós-teste trouxe muito insucesso. No entanto, em uma análise amiúde das provas de cada aluno, observou-se que a maioria dos erros apresentados eram provenientes da restrita manipulação algébrica e a deficiência de interpretação textual.

Considerando aqueles quesitos apontados no pré-teste, o pesquisado, buscou recursos didáticos para um ensino contextualizado, cujo cerne fosse a minimização da lacuna cognitiva anteriormente mencionada. Daí que se desenvolveu a atividade de experimentação voltada à álgebra básica e a interpretação de texto, conjuntamente com o ensino e aprendizagem de probabilidade, isso para que os alunos tivessem êxitos no acerto das questões. Cabe frisar que tal ação só foi possível por se estar desenvolvendo a pesquisa segundo o prisma da educação crítica, cuja intenção vai muito além da simples apresentação do conteúdo, e está comprometida com a formação cidadã desse aluno.

De tal modo, se constatou, nas falas dos alunos participantes, tanto da fase da validação quanto na fase de experimentação didática, que as atividades se mostraram estimulantes e tiveram resultados positivos, sobretudo ao incentivar os alunos, tornando a aprendizagem prazerosa e com mais significado.

Portanto, percebe-se que o objetivo aqui proposto foi cumprido e que a questão de pesquisa levantada respondida, uma vez que as atividades propostas envolveram e despertaram o interesse dos alunos em estudar o assunto de probabilidade vinculado aos mais diversos fenômenos aleatórios presentes no cotidiano; tanto da escola em que estes estão inseridos, quanto da vida social e comunitária de cada um. E, tal fato está bem evidente nos recortes de fala dos alunos participantes da pesquisa, como já foi frisado em parágrafos anteriores, como por exemplo, nas falas dos alunos colaboradores (A), (B), (C) e, (D) sobre , e, nos recostes de fala dos alunos participantes do experimento didático, . ALUNO A7, ALUNO A 12 , ALUNO A 22 , se essa forma de ensinar ajuda o aluno a entender o conteúdo de

Tangram - Revista de Educação Matemática, Dourados - MS - v.2 n. 2, pp. 47-66 (2019) 


\section{$O$ ensino de probabilidade com questões sociais}

probabilidade e, se essa maneira de se ensinar torna o assunto mais atraente e interessante, respectivamente.

Assim, nota-se que a atividade proposta é boa e só vem consolidar a afirmação feita antes, de que esse modo de se ensinar é eficaz e capaz de despertar o interesse e o desejo do aluno em aprender, refletir e, sobretudo, nesse caso, calcular a probabilidade de um evento aleatório acontecer em sua vida o que os tornará cidadãos mais conscientes, críticos e comprometidos em transformar e melhorar a realidade social em que vivem exercendo de maneira justa e profícua seu papel de cidadão consciente de sua realidade política, social e cultural.

Dessa forma, se espera que em futuros estudos o pesquisador busque enfatizar mais sobre essa forma de promover o Ensino, em especial, o de probabilidade, de modo que o conteúdo esteja vinculado a realidade de vida do educando e voltado para as mais diversas situações sociais vivenciadas por tantos adolescentes que cursam o Ensino Médio o que, certamente, tornará tal ensino mais significante e atraente, deixando de lado o modo mecanizado e frio que se tem hoje. Ressaltando que é de suma importância que em estudos posteriores, o pesquisador possa trabalhar questões preliminares a fim de resgatar o conhecimento de base matemática para que o aluno tenha maior facilidade e competência ao resolver questões que envolvam o cálculo de probabilidades provenientes de fenômenos que engloba as problemáticas que traz dentro e fora do ambiente escolar.

\section{Referências}

Abreu, Sónia José Teixeira Faria de. (2012) Educação Matemática Crítica: o seu atributo na formação cidadãos críticos e responsáveis. 91 f. Dissertação (Mestrado em Ensino de Matemática)- Universidade da Madeira. Funchal, 2012.

Brasil. Secretaria de Educação Fundamental. (1997) Parâmetros Curriculares Nacionais (Matemática). Brasília: MEC.

Cabral, Natanael Freitas.(2004) O papel das interações professor-aluno na construção da solução lógico-aritmética otimizada de um jogo com regras. $144 \mathrm{f}$. Tese (Doutorado em Educação Matemática)- Universidade Federal do Pará. Belém.

Canaveze, Leila. (2013) O ensino-aprendizagem de probabilidade em uma escola. 213f. Dissertação (Mestrado em Ensino de Ciências Exatas)-Universidade Federal de São Carlos. São Paulo.

Tangram - Revista de Educação Matemática, Dourados - MS - v.2 n. 2, pp. 47-66 (2019) 


\section{$O$ ensino de probabilidade com questões sociais}

Ferreira, Robson dos Santos. (2011)Ensino de Probabilidade com o uso do programa estatístico $R$ numa perspectiva construcionista. Dissertação (Mestrado em Educação Matemática). Universidade Bandeirante de São Paulo. São Paulo.

Figueredo, Auriluci de Carvalho.(2000) Probabilidade condicional: um enfoque de seu ensino-aprendizagem. 158f. Dissertação (Mestrado em Educação Matemática)Pontifícia Universidade Católica de São Paulo. São Paulo.

Gonçalves, Mauro César. (2004) Concepções de Professores e o ensino de Probabilidade na Escola Básica. Dissertação (Mestrado em Educação Matemática)- Pontifícia Universidade de São Paulo, São Paulo.

Gondim, Hellen Fernandes. (2013) Probabilidade e probabilidade geométrica: conceitos e exemplos aplicáveis no ensino básico. 66 f. Dissertação (Mestrado Profissional)Universidade Federal de Mato Grosso do Sul. Campo Grande.

Iung, Mauricio Osmall. (2013) Questionário Virtual Para o Ensino de Probabilidade. 56 f. Dissertação (Mestrado Profissional em Matemática em Rede NacionalPROFMAT) - Universidade Federal do Rio Grande do Sul. Rio Grande do Sul, 2013.

Lima, Felipe M. Bittencourt.(2013) O Ensino de Probabilidade com o uso do Problema do Jogo dos Discos. 121 f. Dissertação (Ensino de Ciências Exatas)- Universidade Federal de São Carlos. São Carlos.

Neves, Fábio C. de Oliveira. (2015) Ensino de Probabilidade: Tipos de Eventos. Dissertação (Mestrado Profissional em Matemática) - Universidade Federal do Pará, Belém.

Passos, Caroline Mendes dos. (2008) Etnomatemática e educação matemática criticam: conexões teóricas e praticas. 150 f. Dissertação (Mestrado em Educação). Belo Horizonte.

Reis, Jaqueline Ferreira dos. (2010) Etnomatemática, educação matemática crítica e pedagogia dialógico-libertadora: contextos e caminhos pautados na realidade sociocultural dos alunos. 146.f. Dissertação (Mestrado em Educação em Ciências e Matemática)- Universidade Federal de Goiás. Goiás.

Rotuno, Sandra Aparecida Martins.(2007) Estatística e probabilidade: um estudo sobre a inserção desses conteúdos no ensino fundamental. 108. f. Dissertação (Mestrado Em Educação)- Unidade Federal do Paraná. Curitiba.

Souza, André Marcelo Santos de. (2012) Proposta de ensino para conceituação de acaso como introdução ao ensino de probabilidade. 78 f. Dissertação (Mestrado em Ensino de Ciências Naturais e Matemática)- Fundação Universidade Regional de Blumenau. Blumenau.

Vargas, Saulo. (2011) A importância do entendimento do acaso nas experiências aleatórias para o ensino e aprendizagem da probabilidade e da estatística. 84f. Dissertação

Tangram - Revista de Educação Matemática, Dourados - MS - v.2 n. 2, pp. 47-66 (2019) 


\section{O ensino de probabilidade com questões sociais}

(Mestrado em Ensino de Ciências Naturais e Matemática)- Universidade Regional de Blumenau. Blumenau.

Enviado: $18 / 07 / 2018$

Aceito:10/11/2018

Tangram - Revista de Educação Matemática, Dourados - MS - v.2 n. 2, pp. 47-66 (2019) 